\title{
Freud e o Caso AB: entre a esperança e a ruína*
}

\author{
Sérgio de Gouvêa Franco \\ Karin Wondracek
}

\begin{abstract}
O artigo recupera um desconhecido caso de Freud, do qual a correspondência Freud \& Pfister dá fragmentárias notícias. As cartas trocadas entre 1924 e 1927 fornecem informações sobre o encaminhamento, a difícil evolução do tratamento de $A B$ e o sofrimento de Freud ao atendê-lo. Os avanços e recuos do problemático caso estão relacionados com as vicissitudes da vida de Freud, com os avanços da psicanálise e com os acontecimentos sociais e políticos à época. Pacientes como AB, com problemáticas narcísicas e esquizóides, afirma o artigo, continuam chegando aos consultórios dos analistas hoje.
\end{abstract}

Palavras-chave: Caso AB, correspondência Freud \& Pfister, história da psicanálise, personalidades narcísicas e esquizóides

* Este trabalho foi originalmente apresentado em encontro do dia 14 de setembro de 2006 do Laboratório de Psicopatologia Fundamental da PUC-SP. 
Não tente viver para sempre... você não vai conseguir.

Bernard Shaw, citado por Freud (Gay, 1989, p. 386).

\section{Correspondência Karin/Sérgio}

Caro Sérgio:

Passados alguns anos da tradução das Cartas de Freud e Pfister, meus olhos e ouvidos voltam-se para outros aspectos da correspondência. Os conteúdos mais manifestos, já abordados em outros estudos, estão se esmaecendo, e algumas nuanças começam a se destacar. Certas facetas de Freud, não explicitadas em seus escritos e biografias, tornam-se mais palpáveis. Uma delas diz respeito à sua clínica nos anos tardios, após a Primeira Guerra Mundial e durante sua "guerra particular" contra a moléstia na boca. E, neste sentido, gostaria de destacar as cartas que tratam do encaminhamento do paciente $A B$ a Freud. Através delas, penso que podemos conhecer mais da sua clínica madura e também das suas crises enquanto analista que se depara concretamente com sua própria finitude. Que tal investigarmos estes anos, que tal escrevermos sobre o paciente $A B$ ?

Com amizade,

Karin, 22 de novembro de 2005.

Estimada Karin:

Desde sua sugestão de investigarmos o desconhecido caso $A B$ de Freud em fins do ano passado, muito aconteceu em mim acerca deste assunto. Com sua ajuda, mergulhei no clima da clínica freudiana dos 70 anos. Alguém poderia questionar a abordagem de um caso pela 
investigação do analista. Mas não é sempre isto o que temos: o relato do analista acerca do caso? Sabemos que todo caso é uma construção, que inclui a experiência do analista não apenas com aquele paciente, mas com muitos, não apenas com os pacientes, mas com sua própria vida. O caso é particularmente intrigante porque Freud resistiu atender o rapaz. Ao que tudo indica Freud via de algum modo dramatizado neste atendimento seu próprio sofrimento. Claro que Freud não se mistura no paciente, mas dizer que um analista não é atingido pelos seus atendimentos: isto é bobagem. De fato, sempre nos curamos na cura dos nossos pacientes; isto se o atendimento evolui bem.

Apresento um texto que consolida AB em Freud, em mim, talvez em você.

Atenciosamente,

Sérgio, 28 de junho de 2006.

Antecedentes

Situada às margens do Rio Danúbio, a capital da Áustria foi um dos mais importantes centros culturais da Europa no tempo de Francisco José I. O Império Austro-Húngaro foi governado por ele entre 1848 e 1916, período em que a cidade se modernizou e se embelezou; a população cresceu enormemente. Na avenidaanel que a envolvia era possível admirar construções como a Ópera, a Universidade, o Parlamento, erguidas em estilo barroco ou neo-renascentista. Nos séculos XVIII e XIX não havia lócus musical mais importante: Vivaldi, Beethoven, Chopin e Schubert; mesmo que não se deseje é necessário citar Strauss. É a Viena que se orgulha do gênio de Mahler, dos compositores Arnold Schöenberg e Alban Berg, dos pintores Klimt e Kokoschka.

A primeira grande guerra mudou muitas coisas... De capital do Império, Viena passa a capital da pequena república austríaca. São tempos difíceis: fome, insuficiência de aquecimento e iluminação nas casas. Jones diz de Freud: "Era preciso um espírito forte para agüentar ficar sentado, tratando de pacientes, por horas seguidas em um frio mortal, ainda que usando um sobretudo e grossas luvas” (Jones, 1989, v. III, p. 21). O pós-guerra acrescenta preocupações a Freud. Era difícil obter notícias do filho mais velho prisioneiro de guerra na Itália. A 
situação econômica era desanimadora. Freud perdera quase a totalidade de suas economias. Os seus ganhos não acompanhavam a inflação. Decidiu tomar americanos e ingleses como pacientes e analistas em formação, para receber em moeda forte. A separação da Hungria aumentava as dúvidas sobre o futuro da psicanálise. Ferenczi parecia distante em Budapeste. Ainda que houvesse uma boa circulação de suas idéias em Londres, sofria antagonismo no mundo de fala alemã. Os acontecimentos produziram desalento em seu espírito.

\section{0 e 1923}

Dois anos após o término da guerra, Freud sofrerá dois fortes golpes. O primeiro foi a morte de seu amigo Toni von Freund, de um câncer abdominal. Apenas três dias após o seu enterro, chegam notícias de que sua filha Sophie na Alemanha está acometida de grave e inesperada doença. Não havia trens de Viena para a Alemanha. Freud não consegue ir a Hamburgo, mesmo Oliver e Ernst em Berlim só chegam quando sua irmã já estava morta. Freud ficou perplexo, a moça com 26 anos estava com saúde perfeita, feliz, com dois filhos. Ele escreve a Jones comentando a morte da filha: "O pobre ou feliz Toni von Freund foi enterrado na última quinta-feira... Lamento saber que seu pai agora está na lista, mas todos temos de estar e pergunto quando será minha vez. Ontem passei por uma experiência que me fez desejar que não demore muito” (Jones, 1989, vol. III, p. 36). Para Ferenczi diz: “Quanto a nós? Minha mulher está inteiramente arrasada. Penso: La séance continue. Mas era um pouco demais para uma semana” (Jones, 1989, vol. III, p. 36).

1920 pode ter sido difícil, 1923 foi ainda mais. Freud trabalhou o início do ano com a sua força e intensidade habituais. Como os demais anos, ansiava pelas longas férias de verão: passear pelas montanhas, estação de águas, visitas turísticas, pensar e escrever psicanálise. Ele procurava evitar, mas às vezes recebia pacientes nas férias, ou analistas em formação, pessoas que subiam aos Alpes de seu descanso. Sempre se preocupou com a própria saúde, sabia das deficiências de seu coração, mas na verdade até esse ano Freud trabalhou sem poder reclamar de falta de vigor. Ficou sabendo nesse ano do suicídio de sua sobrinha Caecilie Graf com apenas 23 anos. Muito mais significativo para sua biografia foi o reconhecimento, em fevereiro de 1923, daquilo que ele chamou de “um tumor leucoplástico em meu maxilar e palato”. Uma leucoplasia é um tumor benigno associado ao consumo de tabaco, com o que Freud se deliciava. Sabemos que entre (aparentes) erros de diagnóstico e terapêutica, esta suposta leucoplasia virou câncer; Rodrigué sustenta que foi o mau tratamento que provocou o tumor 
maligno. ${ }^{1}$ De qualquer forma, esse tumor na boca de Freud demandou cirurgias sem fim, ajustes, prótese, enorme sofrimento físico e psíquico e finalmente levouo à morte em 23 de setembro de 1939.

Freud foi ver o dermatologista Maximilian Steiner, depois de certa resistência inicial. Em abril de 1923 mostrou sua boca a Felix Deutsch, que havia sido por algum tempo seu clínico geral. Deutsch achou que a lesão era câncer: um epitelioma para usar o termo técnico, mas não revelou sua opinião a Freud. É difícil entender, mas Freud procurou então um médico que, segundo sua própria avaliação, era um medíocre profissional. Marcus Hajek foi quem operou Freud pela primeira vez, no ambulatório de sua clínica. O médico, a clínica, enfim todo o arranjo desta primeira cirurgia é tão improvisado que se abre a possibilidade para uma pergunta. Teriam Freud e Hajek feito uma aliança inconsciente? Não desejaram ambos minimizar os acontecimentos? Hajek trata a intervenção como algo banal. Freud nem avisa em casa. Contudo, algo foi mal durante a operação: a hemorragia foi intensa e o pós-operatório complicado. O local e o atendimento eram inadequados. A noite seguinte quase foi a última de Freud. Junto com Freud, alocado no mesmo quarto, ficou aquele que Anna descreveu mais tarde como "o anão retardado” (Gay, 1989, p. 384). Freud começou a sangrar de madrugada, ele teria apertado a campainha, mas a campainha não funcionava. Freud ficou desamparado. Foi o anão quem saiu para buscar ajuda e a hemorragia foi controlada.

Os discípulos mais próximos tentaram esconder os supostos fatos médicos ao grande nome. Mas Freud reagiu com vigor, esteve contra os que pretendiam minimizar ou negar os acontecimentos. Ele queria viver tudo com coragem, sem retocar a realidade. Em 1923 foram realizadas ainda duas novas operações, conduzidas agora com sucesso pelo especialista dr. Hans Pichler. Freud se preparou para o pior, mas a doença não iria levá-lo senão 16 anos depois. Após as intervenções de 1923, seguiram-se inúmeras pequenas e grandes intervenções, sempre pelas mãos do dr. Pichler. Muito do apego à filha caçula Anna surge no contexto do apoio que dela recebe por conta da doença na boca. 1923, entretanto, tinha ainda mais sofrimentos para impor a Freud...

No verão de 1923, portanto após a primeira cirurgia, Freud está de luto pelo seu amado neto Heinele: o menino de quatro anos era o filho mais novo de Sophie (que morrera em 1920). Freud convivera intensamente com a criança porque Mathilde e o marido - que na prática a adotaram - a trouxeram a Viena por meses. Escrevendo sobre o menino à morte Freud diz: “ele era realmente uma pessoa

1. Emilio Rodrigué faz uma extensa investigação nesta direção sustentando que o câncer de Freud é iatrogênico (Rodrigué, 1995, p. 107-118). 
encantadora, e eu mesmo sei que dificilmente algum dia amei um ser humano, e certamente nunca uma criança, tanto quanto a ele” (Gay, 1989, p. 385). O diagnóstico fatal foi tuberculose miliar. Depois da morte de Heinele, Freud diz: "Estou suportando muito mal essa perda, creio que nunca experimentei nada mais duro... Fundamentalmente tudo perdeu seu valor” (p. 386). Freud estava mais abatido com a perda do neto do que com o diagnóstico de câncer. Peter Gay (1989) produz uma frase forte, depois que sua "querida criança” morreu, Gay diz: “o homem sem lágrimas, chorou” (p. 386). Escrevendo para Ferenczi diz: "Isso está ligado a meu atual desgosto pela vida. Nunca tive uma depressão antes, mas agora deve ser uma” (p. 386). Para Eitingon escreve em agosto: “Ainda estou sendo torturado na boca e obcecado por uma saudade impotente pela querida criança”.

Três anos mais tarde, em 1926, escrevendo para Binswanger que perdera um filho, Freud compara os sofrimentos e explica o seu: "Eu suportei admiravelmente bem [a morte de Sophie]. Era o ano de 1920, estava-se esgotado pela miséria da guerra, preparado durante anos para ter a notícia de que se perdera um ou até três filhos. Assim, a resignação ao destino estava pronta.” Mas a morte do neto representava em sua mente a morte de "todos os meus filhos e os outros netos, e desde então, desde a morte de Heinele, não me interesso mais por meus netos, e também não tenho mais prazer na vida. Este também é o segredo da indiferença - as pessoas chamam de coragem - com relação ao perigo para a minha própria vida”. Quando Ernest, o irmão mais velho de Heinele, aquela figura ao mesmo tempo famosa e desconhecida do Fort-da, veio passar uns dias com os Freud, no ano de 1923, Sigmund afirmou: "não o considerei nenhum consolo” (Gay, 1989, p. 387).

\section{Rank e Abraham}

Freud chega ao meado dos anos 1920 com grandes questões intelectuais, que nem de longe eram puras abstrações para ele. Tudo passava por sua clínica e pelos acontecimentos pessoais e sociais. Os sentimentos privados e as generalizações científicas se retro-alimentavam. Freud era muito cuidadoso, rigoroso, não confundia os planos, mas sua ciência nascia de sua vida. Nas mãos de nossos adversários intelectuais, a frase é munição para desvalorizar Freud e a psicanálise. Algum objetivante quererá a separação metodológica radical do sujeito e do objeto do conhecimento. Quem desvalorizará a herança cartesiana? O que não se poderá deixar de destacar é o arsenal intelectual e técnico que Freud criara, exatamente para estudar a subjetividade humana. A assepsia metodológica positivista ganha 
nota dez, mas à sua frente o objeto de estudo desaparece: onde está a subjetividade humana? O jogo delicado, intrincado, arriscado, que reconhece a circulação da transferência é o que permite manter vivo nosso objeto de estudo. Não há escape: para estudar o humano é preciso sujar as mãos no humano.

A esta altura da vida, Freud não queria perder amigos, parentes, discípulos. Ele considerava Otto Rank inteiramente confiável. Depois da guerra era tão leal que Freud o tomava de modo filial. Alguns anos depois começara a manifestar opiniões que apontavam o desfecho inteiramente inesperado para este relacionamento. “Inibições, sintomas e ansiedade”, de 1926, só pode ser entendido à luz das dificuldades entre Freud e Rank. Freud tinha investido muito nele desde 1905, quando aparecera com seu manuscrito “O artista” à mão. Apoiara a sua formação como analista, nomeara-o para redigir atas do grupo das quartas-feiras e incentivara sua participação nas reuniões, empregara-o como assistente editorial, ajudara a financiar seus estudos e viagens de férias. Fazia parte daquele pequeno grupo que circulava muito próximo de Freud. Rank, a caçula Anna e Pfister foram os primeiros analistas leigos, aconselhados por Freud a dispensar o estudo da medicina como pré-requisito para a prática da psicanálise. Rank retribuía o prestígio que lhe dava Freud com trabalho: escrever, editar e analisar.

Freud foi o último a suspeitar de Rank, ou o último a admitir qualquer suspeita acerca dele. O livro que escrevera em parceira com Ferenczi $O$ desenvolvimento da psicanálise apontava certo otimismo terapêutico que contrariava a idéia que a análise é trabalho árduo e extenso. Mas certamente o conflito tem a ver com a publicação de $O$ trauma do nascimento, em 1923. Dedicado a Freud, o livro aponta para o nascimento como a origem principal da angústia, não os conflitos posteriores no circuito filho, mãe e pai. Freud não reagiu ao livro. Tentou desfazer o sentimento entre os mais próximos que Rank era o novo Adler ou Jung. Minimizou as diferenças, lutou para desfazer mal-entendidos. Abraham levantou armas contra Rank, Jones acompanhou Abraham, Ferenczi defendeu seu parceiro de livro. Em 1924, Rank foi para o EUA: as disputas seguiram por carta. Um psiquiatra americano escreveu a Freud dizendo que Rank falava heresia nas Américas. Freud escreveu de volta minimizando. Escreveu também a Rank, aconselhando-o a deixar um caminho aberto na direção das posições partilhadas pelo resto do grupo. Eitingon divulga na Europa pensamentos contra Rank, Anna também. De volta a Viena, enaltecido pelo destaque encontrado na América, Rank renuncia a seus vários cargos no círculo psicanalítico. Ferenczi pára de defendê-lo. Para tristeza de Freud, Otto Rank vai embora.

No verão de 1925, Freud tem algo mais com o que se preocupar além da defecção de Rank: a saúde de Abraham. Abraham escreve da cama para Freud. Tinha voltado de uma série de conferências na Holanda com bronquite. Entre pioras e melhoras, o pulmão de Abraham não sara. Assim mesmo ele vai ao 
Congresso de Psicanálise em Hamburg, mas sua saúde piora. Acessos de febre, dores, problemas na vesícula biliar, complicações pulmonares indicavam que a doença era grave. Em dezembro, Freud se angustia acerca do amigo. Deutsch, o médico de Freud, foi ver Abraham e advertiu para a possibilidade do pior. Dias depois, no dia de Natal, com apenas 48 anos, morre Abraham. "A morte de Abraham foi muito dura para Freud. O organizador sensato, o renomado formador de analistas, o otimista indispensável, o teórico interessante, o amigo leal tinha partido" - escreve Gay (1989, p. 439). No obituário escrito por Freud, ele acusa o enorme sentimento de perda: "Enterramos com ele... uma das esperanças mais firmes da nossa ciência, jovem como é e ainda tão implacavelmente agredida, e uma parte do seu futuro que agora, talvez, seja irrealizável” (Freud, Karl Abraham, 1926, p. 269).

\section{Pfister e a correspondência com Freud}

Oskar Pfister, neste cenário de perdas dos últimos anos de vida de Freud, aparecia valorizado. Quem perdera Adler e Jung, quem perdera Rank e Abraham, tinha uma gratidão ao pastor suíço que preferira ficar ao seu lado a seguir Jung - muito mais favorável ao fenômeno religioso. Já em 1909, Freud o descrevera da seguinte maneira: "Nenhuma visita, desde a de Jung, teve tanto impacto nas crianças e trouxe tanto bem-estar a mim mesmo" (Freud \& Pfister, 1998, carta 8, 12.7.1909, p. 39). Anna Freud confirma em escrito de 1962:

No ambiente doméstico dos Freud, alheio a toda vida religiosa, Pfister, com seus trajes, aparência e atitude de um pastor, era aparição de um mundo estranho... Seu calor humano e entusiasmo, sua viva participação também nos fatos mínimos do cotidiano entusiasmavam as crianças da casa e faziam dele um hóspede bemvindo em qualquer tempo, uma figura humana ímpar em seu modo de ser. Para eles, segundo um dito de Freud, Pfister era não um "santo homem", mas um tipo de "flautista de Hammelin", que só precisava tocar seu instrumento para ter um bando inteiro obediente atrás de si. (Freud \& Pfister, 1998, p. 19)

Ainda que não partilhasse dos pontos de vista religiosos do psicanalista pastor, Freud o respeitava. Não dispensou sua amizade até o fim, especialmente nos momentos em que a vida lhe parecia mais dura.

A correspondência Freud \& Pfister é a terceira coletânea de cartas da mão de Freud conhecida do público em geral. Temos as cartas de Freud a Fliess dos anos formativos de 1887 a 1902. Há uma segunda coletânea de cartas pessoais dirigidas a 102 destinatários, que cobre praticamente toda a vida de Freud. A correspondência Freud \& Pfister cobre os últimos trinta anos da vida de Freud, 
entre 1909 e 1939. Infelizmente só parte das cartas trocadas entre eles está disponível. Originais se perderam no processo de emigração para a Inglaterra, outra parte foi destruída por Freud, conforme o desejo de Pfister, expresso em carta de 1.6.1927. Anna Freud teve papel importante na preservação e publicação das cartas em alemão. Quando Pfister cede sua parte do material, apenas pediu a ela que fosse omitido o material "que pudesse ferir pessoas vivas" (Freud \& Pfister, 1998, p. 19). Publicadas na década de 1960 em alemão, chegam tardiamente ao público luso-brasileiro em 1998.

A honestidade é o tom que permeia a correspondência; os temas pessoais e religiosos são discutidos, como esclarece Joel Birman (1988), em "um diálogo amigo e cordial” (p. 123). Há muitos detalhes da vida de ambos, há referências aos grandes nomes e menções rápidas aos pacientes. É possível acompanhar o desenrolar de muitos acontecimentos da vida de Freud lendo as cartas. Em fevereiro de 1924, por exemplo, Freud agradece a Pfister por não falar no câncer: "Entre meus amigos o senhor é o único que não se refere por escrito à minha doença" (carta 66, 26.2.1924, p. 124). Em maio de 1925, Freud conta que vai mandar colocar uma foto de Pfister em sua sala, após receber uma saudação pelo seu aniversário: "O senhor foi um dos poucos que, apesar da distância, cumprimentou-me de modo pessoal. Por isso o senhor ocupará também, depois de alguns dias de incubação, um lugar na minha sala para morar definitivamente entre pessoas com idéias afins” (carta 71, 10.5.1925, p. 130). Frente ao abatimento de Freud após tantas perdas, Pfister procura animar o amigo, em 1925:

Sua tendência à resignação me entristece. Se pudesse tomá-lo pela palavra, eu teria a objetar que o senhor está concedendo ao seu Isso plein pouvoir sobre vida e morte, felicidade e infelicidade. Eu protestaria, em nome de sua amável filha, da querida esposa, de toda a sua família, da ciência e de todo o panteão das potências superiores.

\section{AB}

Na coletânea de cartas Freud \& Pfister encontramos também, algo surpresos, detalhes de um caso praticamente desconhecido da clínica de Freud. Um verdadeiro achado porque como destaca Roazen (1999): “à medida que Freud envelhecia, seus escritos se tornaram cada vez mais distantes das preocupações clínicas práticas” (p. 22). As referências a AB são incompletas, mas o material que aparece é suficiente para ser instigante. O que está nas cartas monta um quadro que clama por pensamento. É necessário trabalho para completá-lo. 
Aparentemente trata-se de paciente do qual o próprio Pfister se ocupa na Suíça. Não se sabe a razão, ele mudará para Viena. Pode até ser que fosse a Viena em busca de Freud. Pfister pede ajuda para o rapaz. Freud tem dificuldades de se colocar no lugar de analista do rapaz e quer passá-lo a outro profissional. A primeira referência aparece em uma carta de Freud a Pfister de 21.12.1924:

Não se preocupe com seu jovem americano. O homem pode obter ajuda. Aqui em Viena, o dr. Reik especializou-se justamente nessas neuroses compulsivas graves. Tratou, por exemplo, por vários anos, com extrema paciência e profunda compreensão, e também não sem sucesso, um conde russo que lhe pude enviar. (carta 69, p. 129)

Ficamos sabendo assim que o paciente é um jovem americano radicado na Europa, necessitando de ajuda para uma neurose que Freud classifica de "compulsiva grave". Trabalho que exige do clínico "paciência e profunda compreensão”, mas Freud tem esperanças de cura. Não se sente, todavia, pessoalmente atraído pelo caso, prefere remetê-lo a Theodor Reik, psicanalista que trabalhava não apenas em Viena, mas também em Nova York.

No início de 1924, Pfister teria remetido outra pessoa a Freud, referida apenas pela letra F. Freud está tão preocupado com sua saúde que pensa em não aceitá-lo:

O senhor escreve que no verão eu deveria aceitar F. em análise. É difícil que me comprometa para o verão, pois não estou seguro quanto ao futuro. Mas, se eu puder, certamente o farei, desde que ele também venha por livre vontade. Além disso, não se esqueça que não trabalho nos meses de verão propriamente ditos. (carta 65, 4.1.1924, p. 122 e 123)

Freud tem o mesmo pensamento em relação ao jovem americano: crê que por razões de saúde não poderá acompanhá-lo.

Freud não fora ao Sexto Congresso Psicanalítico Internacional em Salzburg em 1924; preferira descansar em Semmering. Ele se poupa, mas Pfister insiste que Freud mesmo atenda o rapaz americano. Frente à insistência, antecipando uma visita de Pfister a Viena, durante a Páscoa de 1925, Freud aceita ver o rapaz:

... me traz a expectativa de tê-lo conosco em Viena, na Páscoa. Traga junto o seu americano. Não estou declinando nem um pouco em aceitá-lo para tratamento a partir de outubro, já que o senhor se empenha tanto por ele. Não é verdade que eu, por princípio, só aceite médicos. Tenho, também entre minhas cinco horas, dois pacientes e com prazer providencio um terceiro para a próxima saison. Meus honorários correspondem a 20 dólares a hora para todos. Visto que a natureza parece ter o objetivo de me conceder um ou mais anos de honra, não preciso rejeitar pacientes com tanto temor. O principal, é claro, será a impressão que o jovem causará em mim no nosso encontro. Até outubro o senhor mesmo terá de 
ficar com ele, pois absolutamente não vejo possibilidade de tomá-lo antes. (carta 70, 22.2.1925, p. 129 e 130)

AB parece ganhar espaço na clínica de Freud porque Pfister insiste - a questão dos encaminhamentos tem aqui um ponto que nos chama a atenção: "Não estou declinando nem um pouco em aceitá-lo para tratamento a partir de outubro" - a frase se torna afirmativa pelas duas negativas - talvez mostrando sinais de lutas íntimas de Freud em receber o paciente: “... já que o senhor se empenha tanto por ele”. Sabemos que abrir espaço no afeto e na agenda é algo da ordem do desejo e da realidade, da contratransferência e da identificação. A atitude receptiva para com $A B$, que vai se instalando em Freud, aos poucos, parece respaldada no seu relacionamento com Pfister.

A esta altura da vida Freud reduziu sua cota de trabalho a cinco horas diárias; parte substantiva desse tempo é gasta com análises formativas, especialmente de médicos ingleses e americanos. Freud procura se poupar, só tem duas ou três pacientes. Está preocupado com o seu sustento, cobra um valor bem elevado por sessão. Mas como vai aos poucos saindo da crise pessoal de 1923, o seu pensamento já aceita que viverá uns poucos anos mais: “a natureza parece ter o objetivo de me conceder um ou mais anos de honra, não preciso rejeitar pacientes com tanto temor”. Acabar recebendo AB, encaminhado por Pfister, pode ter sido uma decisão de Freud que reforça em sua vida pessoal a força de eros na luta contra thanatós.

Em maio de 1925 Freud relata a Pfister o encontro que teve com os pais do rapaz:

Conheci pessoalmente os pais do seu protegido. Eles parecem bastante dispostos a fazer sacrifícios, o que geralmente indica um mau prognóstico. Não pude prometer-lhes nada concreto, apenas expressar-lhes genericamente minha disposição. Talvez eu já possa aceitar o rapaz em $1^{\circ}$ de setembro, ao invés de $1^{\circ}$ de outubro. Até lá, é meu desejo intenso que ele permaneça com o senhor. O pai é, creio eu, bem flexível. Mas a mãe parece mais intranqüila e mais disposta a planos independentes. Talvez ainda falaremos dele mais vezes. (carta 71, 10.5.1925, p. 131)

Não se pode dizer ao certo a idade do rapaz, talvez não estivesse muito além do fim da adolescência: 18 ou 19 anos? Se Freud aceita ver primeiro os pais, estamos falando de um jovem; um jovem em um quadro certamente grave. Freud apela a Pfister para que cuide do rapaz até que ele possa tomá-lo em atendimento em outubro, na melhor das hipóteses em setembro.

Freud se espanta com a prontidão da família em fazer "sacrifícios”. Considera isto "um mau prognóstico". A palavra sacrifício é uma palavra usualmente empregada no contexto religioso. Talvez fosse uma família religiosa: o rapaz seria um americano judeu, um americano cristão? Pfister circulava não 
apenas no mundo psicanalítico, mas também no religioso. Freud, por sua vez, conhece a tradição judaica do sacrifício muito bem. O mau prognóstico poderia ser porque Freud entende que quem se sacrifica pode cobrar grande retribuição de quem se beneficia do sacrifício. Seria este o rápido diagnóstico familiar de Freud? Ele percebe o pai "bem flexível”, portanto como um fator familiar positivo no tratamento. Mas a mãe inspira preocupação, por ser intranqüila e não disposta a aderir ao espírito do tratamento. Mas Freud ainda não tomou a decisão de aceitar o rapaz em análise: "não pude prometer-lhes nada de concreto".

Durante as férias de verão de 1925, em Semmering, Freud não se esquece do jovem americano. Luta em seu espírito acerca do lugar que ele vai ocupar em sua clínica. Imagina talvez em recebê-lo nos Alpes, mas desiste da idéia. Sua linguagem expressa dúvida:

No que toca ao nosso esperançoso rapaz, penso que o senhor deve deixálo ir para sua ruína. É verdade que existe uma possibilidade incerta de que eu possa aceitá-lo a 15 de setembro, talvez até já no dia $1^{\circ}$, mas a dificuldade quase intransponível é que aqui em Semmering não há nenhuma ocupação para ele, pela sua condição insociável. Assim eu correria o risco de ter de me envolver com ele de modo intenso demais. Em Viena isto se regularia por si só. (carta 72, 10.8.1925, p. 131)

Aos poucos Freud permite que uma imagem mais densa do rapaz vá se formando dentro si. Ele não é mais “o seu jovem americano”, nem "o seu protegido", possessivos referidos a Pfister. Passa a ser o "nosso esperançoso rapaz”. Já divide a posse com Pfister, em clara passagem e transição.

Freud tem "temor" de tomar pacientes. Luta com sentimentos acerca de sua própria debilidade e doença, está cansado de perdas, antecipa sua própria morte. Não há como não pensar que Freud olha para esse paciente de um modo a ver dramatizado nele a sua própria vida. Se não for assim, como entender a enigmática e contraditória expressão: "No que toca ao nosso esperançoso rapaz, penso que o senhor deve deixá-lo ir para sua ruína”. Esperança e ruína. São temas que se referem ao tratamento do rapaz, são temas que se referem à vida do próprio Freud. Teme excesso de proximidade com o rapaz, se for atendido em Semmering. Um caso grave, muito grave, inteiramente aos seus cuidados em suas férias de verão nas montanhas? Um paciente “insociável”, sem ocupação, que teria que cuidar como hóspede? É fácil imaginar o que pensa Freud: “não quero isto para mim”. É como se dissesse em uma atitude de autodefesa: "longe casos complicados e difíceis, cuido primeiro de mim!”.

Pfister luta com Freud para que não se entregue à doença e velhice: "Neste contexto (...) não posso reunir a necessária reverência diante de suas reclamações pela velhice” (8.10.1925, p. 132). Por fim, Freud atende o rapaz. 
Logo depois que lhe revelei meu plano com $A B$, uma reação tomou conta de mim. O pobre rapaz deu-me pena, também se achou um horário melhor, talvez eu próprio tenha vencido um acesso de desânimo. Em resumo, eu lhe telegrafei: "por enquanto não faça nada", e decidi-me pelo caminho mais vagaroso, de escrever diretamente aos pais. Fui bem franco com eles; dos meus três motivos para abandonar o paciente, compartilhei com eles ao menos dois: a constatação de que ele necessita de uma influência que perdure por anos, que talvez eu não pudesse levar a termo, e a preocupação de que seu estado aceitaria uma mudança para mais grave. O último motivo - que eu quero me poupar de um grande tormento - retive para mim. Depois lhes dei a opção de deixá-los continuar em tratamento comigo, mesmo após estas colocações, ou buscá-lo. A primeira alternativa seria for better for worse, para saúde ou ruína, sem responsabilidade pelas possíveis perturbações de ambos os lados. Eu também os informei do complô com o senhor em Zurique, que agora, após os seus esclarecimentos, me parece desnecessário. Penso que, em todo o caso, fiz algo bom. Ou os pais o buscarão agora, eu estou livre da difícil e provavelmente ingrata tarefa, ou, se o deixarem continuar, minha posição estará substancialmente fortalecida. Depois das observações na sua carta, que testemunham a incompreensão da mãe, a primeira saída será a mais provável, e não terei pena dele.

Acho lisonjeiro que o senhor ainda tenha tanta confiança em mim, mas há de concordar que não seria contra o curso da natureza se desta vez o senhor não tivesse razão. Eu estou cansado, o que é compreensível após uma vida penosa, e creio ter conquistado honestamente o direito ao descanso. Os elementos orgânicos, que tanto tempo agüentaram unidos, querem apartar-se; quem os obrigaria a permanecer no conjunto?

Sobre todos os demais acontecimentos do caso AB, eu o informarei no devido tempo. (carta 73, 11.10.1925, p. 133 e 134)

Freud diz que só conseguiu recebê-lo depois que superou "um acesso de desânimo”. Reconheceu que podia oferecer um horário mais confortável para o rapaz, porque sua negatividade havia diminuído. De qualquer forma, depois do encontro com $\mathrm{AB}$ sentiu pena dele.

O rapaz passa a ser chamado de $A B$, talvez A.B., indicando a abreviatura de dois nomes. $\mathrm{O}$ editor alemão das cartas indica em nota de rodapé que $\mathrm{AB}$ é o jovem americano. Freud continua se relacionando com ele de modo contraditório. Fala de um plano para $\mathrm{AB}$, que depois produz uma reação em si mesmo. Seria um plano para mandá-lo a outro médico? A uma clínica? Para outra cidade? De qualquer forma o plano foi abortado. Freud escreve a Pfister: "por enquanto não faça nada”. Em substituição ao plano original, Freud resolve escrever aos pais do paciente. Freud apresenta dois motivos para não continuar o tratamento. Diz que o tratamento ideal seria longo e que ele, Freud, não sabe por quanto tempo ainda continuaria atendendo. O segundo argumento ainda mais difícil para os pais 
ouvirem se referia a uma opinião forte de Freud em relação a pacientes graves. Freud temia que começada a análise, as defesas do paciente diminuíssem e ao invés de melhorar AB poderia ficar em uma situação mais grave. Freud claramente temia uma evolução paranóide. Havia um terceiro argumento para não dar continuidade ao tratamento que Freud não contou aos pais de $A B$, contou apenas a Pfister: "quero me poupar de um grande tormento". Freud temia sofrer grandemente com esse atendimento. A pergunta importante é qual a razão deste seu grande temor? Por que o atendimento de AB atingiria Freud que adoecia com câncer e que sofria com a perda de seu netinho?

A disjuntiva que Freud colocou para os pais de AB, qualquer desfecho que encontrasse, o fortaleceria diante do caso. Os pais poderiam vir de Zurique buscar o filho, Freud respiraria aliviado por não ter que enfrentar um caso tão perturbador para ele. Ou os pais poderiam deixá-lo em Viena com Freud. Neste caso Freud também se sentiria aliviado, porque se ele abandonasse o caso mais tarde por doença ou mesmo morte, os pais já estavam avisados. Ou se AB entrasse em um surto grave e sem retorno, também sobre isto os pais já estavam avisados. Freud diz que em carta perdida de Pfister, este se referiria à "incompreensão da mãe”. Freud acha que os pais vêm buscá-lo. E acaba contradizendo o que agora mesmo tinha dito, anuncia que se os pais viessem buscá-lo não sentiria pena do rapaz.

Freud se despede agradecendo a confiança que Pfister dispensa a ele como profissional. Finaliza anunciando de modo algo melancólico a sensação de que seu corpo está se despedaçando. Diz que prefere descansar a atender o rapaz. De qualquer forma os pais de $\mathrm{AB}$ deixam que o tratamento prossiga em Viena. No início de 1926, após lamentar a morte de Abraham no natal de 1925 e antes de comentar a publicação de "Inibição, sintoma e ansiedade”, escrito em grande medida como uma resposta ao pensamento de Rank, Freud fala outra vez do atendimento de $\mathrm{AB}$ :

Com nosso rapaz $\mathrm{AB}$ estou numa situação singular. Minha convicção médica, de que ele se encontra na fronteira de uma demência paranóide, aumentou. Estive bem próximo de mais uma vez desistir dele, mas algo tocante que ele tem em si me detém, e diante da ameaça de interrupção ele novamente se tornou meigo e acessível, assim que mantemos atualmente um bom entendimento mútuo. O período da grande piora, em que também escrevi ao senhor, bem pode estar relacionado ao fato de que lhe expus o segredo da sua neurose, o qual provavelmente adivinhei de forma correta. A reação, depois desta revelação, tinha de ser um grande incremento das resistências. O que me traz dificuldade no caso dele é a convicção de que terminará muito mal, se não terminar bem. Isto é, sem maiores escrúpulos, o moço vai se retirar do mundo. Por isso não quero falhar em nada que possa evitar este desfecho. (carta 74, 3.1.1926, p. 135 e 136) 
Freud tem agora um diagnóstico cada vez mais complexo. O rapaz está na "fronteira de uma demência paranóide”, mas continua falando em uma "neurose”. Freud está cada vez mais preocupado com o caso. Ele acha que se o rapaz não apresentar uma melhora, em breve fará um surto definitivo: “o moço vai se retirar do mundo”. Ou estaria falando com estas palavras da possibilidade de suicídio? Freud segue o tratamento carregado de dúvidas, pronto a desistir, mas "algo tocante que ele tem em si me detém”. O que será de AB que toca Freud? Além disto, Freud teria ameaçado o rapaz com a interrupção do tratamento, o que teria feito o seu comportamento mais dócil. Freud pensa que as dificuldades são resultantes das resistências usuais do tratamento da neurose. Mas teme que algo muito ruim se dê com $\mathrm{AB}$ e está disposto a fazer de tudo para que isto não aconteça. Após o descrédito inicial, Freud se sente seguro como analista para tentar evitar o pior para o paciente.

No verão de 1926, Freud está outra vez em férias com a família, nos Alpes, em Semmering. Por incrível que possa parecer: quem é que está com Freud nas alturas? O jovem paciente americano, AB. Nada de grave tinha com ele acontecido:

Estou passando um tempo agradável aqui - até o ponto em que meus sofrimentos localizados o permitem - e quero prolongá-lo até o final do mês. AB, que esteve comigo desde $1^{\circ}$ de agosto, eu o enviarei amanhã em férias até $1^{\circ}$ de outubro. Tenho de lhe dar notícias dele, algumas coisas mudaram. Felizmente foi vencida sua insuportabilidade, eu até me afeiçoei a ele, e parece que ele retribui. Depois de um terrível esforço conseguimos clarear algumas partes da sua história evolutiva íntima, e o efeito disto foi bem favorável, como também o confirmaram parentes que o viram nas férias. Externamente ele se comporta de modo insuficientemente excêntrico e ainda está muito longe do normal, como corresponde à incompletude dos nossos resultados. Por outro lado é inegável que muitos elementos nele sejam realmente inquietantes (Unheimlich), como se ele estivesse no caminho da neurose compulsiva à paranóia. Suas idéias e conexões de pensamento têm freqüentemente algo estranho, e seus sintomas poderiam ser chamados sem constrangimento de idéias delirantes. Toda vez que ele entra em contradição eu me digo que, afinal, é uma esquizofrenia, e quando algo se aclarou, perde-se esta má impressão. Penso que deixarei de lado a pergunta médica pelo diagnóstico e trabalharei adiante no material vivo. Enquanto se mostrar maleável e tivermos sucessos, sinto-me justificado. Não sem importância é a impressão de que a pessoa dele vale todo o esforço. (carta 76, 14.9.1926, p. 141 e 142)

Aparentemente as férias fazem bem para Freud: até o relacionamento com o paciente melhora. O próprio tratamento avança. O diagnóstico permanece o mesmo: alguém a caminho da neurose à paranóia. O contato com o paciente produz aqueles sentimentos estranhos e inquietantes (Unheimlich) que os pacientes graves produzem. Acha que seus pensamentos são francamente 
delirantes. É esquizofrenia, mas por vezes a má impressão passa. Freud desiste de se ater a um diagnóstico fixo e se apega à psicodinâmica. Ele está convencido de que o esforço e o sofrimento do analista valem a pena para ajudar AB.

Em abril de 1927, com quase 71 anos, Freud continua lutando com os efeitos doloridos de seu câncer e continua lutando com seu paciente grave: um consolo para quem luta com vicissitudes semelhantes:

Hoje eu tenho um dia aborrecido, a prótese está me torturando... Dei seu Auto-retrato para AB ler e constatei, nas suas reações inapropriadas, o pouco êxito que tive com ele até aqui. Ainda não abandonou suas reações infantis face à influência da autoridade. Isto torna o tratamento muito difícil para ele. Eu não me detenho na pergunta pelo diagnóstico; ele certamente tem traços bastante esquizofrênicos, sem que por isso já o queira rejeitar. Pois não está claro o que este diagnóstico contém. Mas o sujeito é uma prova dura. Eu agora me debato com ele, exigindo que intencionalmente se oponha à masturbação fetichista, para ver se tudo que foi adivinhado por mim sobre a natureza do fetiche se comprova pela experiência própria. Porém, ele não quer crer que tal abstinência possa conduzir a isso, e que seja imprescindível para o prosseguimento da cura. Por outro lado, não posso, estando ligado a ele por tanta simpatia, decidir-me a mandá-lo embora e arriscar um desfecho negativo. Assim, continuo nos meus intentos, e possivelmente ele escape de mim quando eu efetivamente parar de trabalhar. (carta 78, 11.4.1927, p. 143 e 144)

Para complicar o diagnóstico, Freud inclui o elemento fetichista. Exige o fim da masturbação, mas o paciente reage. Será que esta resistência a parar de se masturbar poderia ser associada a esta mãe que Freud diz "está disposta a planos independentes”? O tratamento é duro para AB. É duro para Freud. Freud tem vontade de desistir, mas está por demais afeiçoado a AB para deixá-lo. Segue o quanto pode; imagina que enquanto trabalhar continuará a atendê-lo.

Em outubro de 1927, dois anos após o início do tratamento, quase três desde que a correspondência sobre AB começara, Freud continua lutando: “AB tem, sem dúvida, muitos traços paranoides - mas nós não podemos prosseguir o trabalho sem perspectiva” (carta 81, 22.10.1927, p. 151). No final de 1928, após uma intensa discussão sobre os temas religiosos de "O futuro de uma ilusão" em várias cartas, Pfister volta à carga com AB: faz uma pergunta técnica: “A outra pergunta concerne à técnica... isto não foi possível, por exemplo, com o nosso AB... O senhor considera minhas tentativas inadequadas?” (carta de Pfister a Freud de 16.11.1928, p. 165 e 166). Como seria bom ter alguém para responder as questões técnicas que a clínica com pacientes como AB suscita! Pfister pergunta e não sabemos a resposta de Freud... Pergunta que nos aproxima do tema angustiante sobre a técnica com pacientes fronteiriços, psicóticos, somatizantes, com distúrbios graves de alimentação... AB precursor destes pacientes atuais? 
Freud estaria pensando nas mudanças técnicas que a compreensão que estes pacientes nos trazem provoca?

Nada mais se menciona sobre este paciente, mas ainda é possível continuar a pesquisa... Para construir a relação de Freud e seu paciente perguntamos pelos acontecimentos sociais e políticos, pelos acontecimentos pessoais da vida de Freud, pelos seus escritos, pelos sentimentos do analista à época do atendimento, conscientes de que estes elementos mutuamente se influenciam. Roazen destaca a mútua influência entre os escritos e a vida de Freud: "deve haver um relacionamento recíproco entre a vida de Freud e seus escritos, de modo que nós possamos acabar voltando aos seus textos com uma compreensão enriquecida” (Roazen, 1999, p. 272).

\section{A entrevista com Freud concedida ao jornalista Sylvester Viereck}

No verão de 1926, Freud está nos Alpes austríacos, em férias. Mais precisamente está em Semmering. Semmering faz parte do colo dos Alpes orientais, está a cerca de $980 \mathrm{~m}$ de altitude e cerca de 2 horas de trem de Viena. Veja foto atual da região.

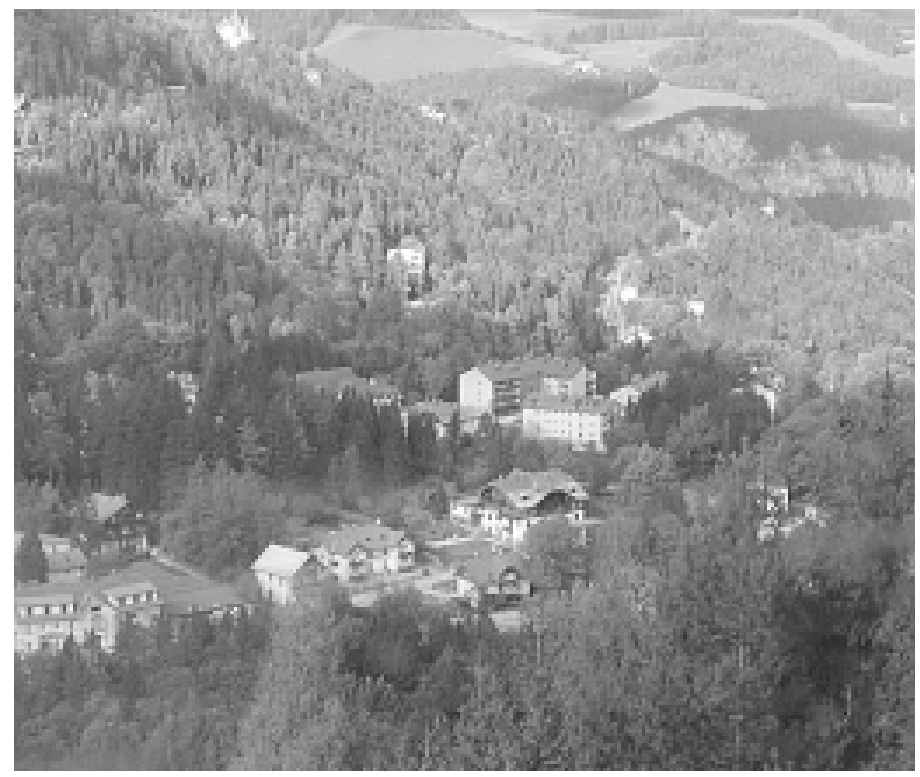


Lá atende AB, como já foi dito. Nessas mesmas férias em Semmering, Freud concedeu uma rara entrevista ao jornalista americano George Sylvester Viereck. Acreditava-se que o conteúdo dessa entrevista, provavelmente publicado na imprensa americana da época, estivesse perdido. Entre as preciosidades encontradas na biblioteca da Sociedade Sigmund Freud, entretanto, está a entrevista. Reproduzimos abaixo uns poucos fragmentos da versão em português de Paulo César Souza. É notável para os interesses deste artigo, que quanto o jornalista pergunta pela clínica de Freud, ele responde: "estou trabalhando num caso muito difícil”. É bem provável que Freud estivesse falando de AB. Quem sabe?

A entrevista começa ao ar livre, entrevistado e entrevistador caminhando pelo jardim da casa onde Freud se hospeda. O caminho bem poderia ser como o da foto abaixo.

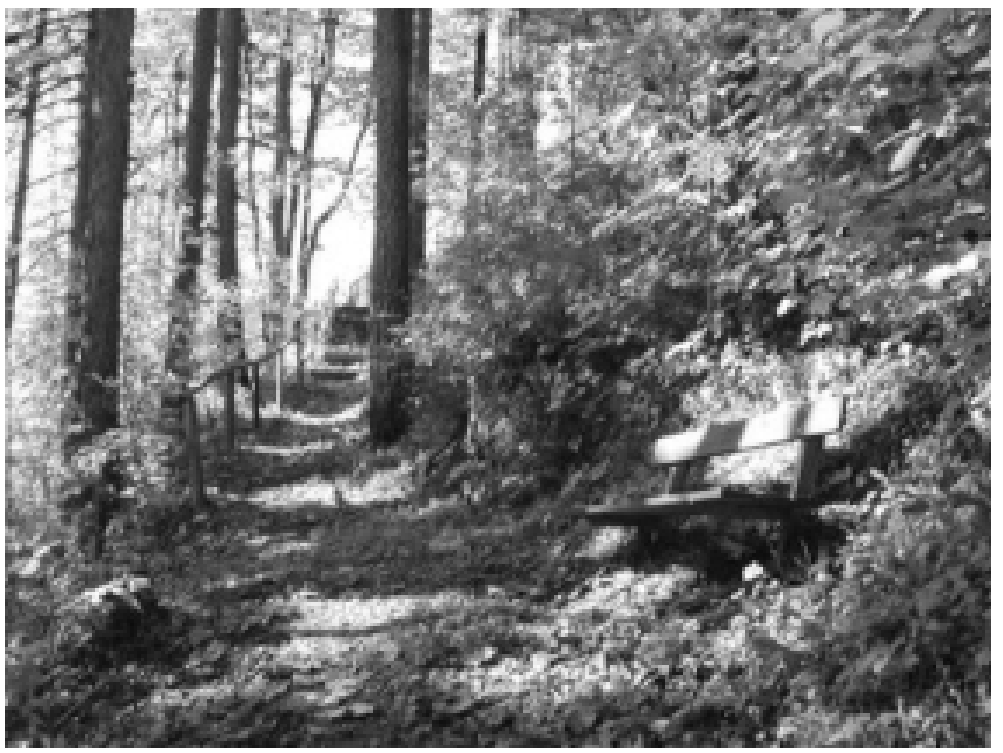

É Freud quem começa a conversa, falando dos seus 70 anos, recémcompletados, fala também dos mal-estares que a prótese na boca lhe causava.

Setenta anos ensinaram-me a aceitar a vida com serena humildade... Detesto o meu maxilar mecânico, porque a luta com o aparelho me consome tanta energia preciosa. Mas prefiro-o a maxilar nenhum. Ainda prefiro a existência à extinção. Talvez os deuses sejam gentis conosco, tornando a vida mais desagradável à 
medida que envelhecemos. Por fim, a morte nos parece menos intolerável do que os fardos que carregamos.

Por que (disse calmamente) deveria eu esperar um tratamento especial? A velhice, com sua agruras, chega para todos. Eu não me rebelo contra a ordem universal. Afinal, mais de setenta anos. Tive o bastante para comer. Apreciei muitas coisas - a companhia de minha mulher, meus filhos, o pôr-do-sol. Observei as plantas crescerem na primavera. De vez em quando tive uma mão amiga para apertar. Vez ou outra encontrei um ser humano que quase me compreendeu. Que mais posso querer?

O jornalista interpela: Então o senhor é, afinal, um profundo pessimista?

Freud responde: Não, não sou. Não permito que nenhuma reflexão filosófica estrague a minha fruição das coisas simples da vida.

Jornalista: Isto é a filosofia da autodestruição. Ela justifica o autoextermínio. Levaria logicamente ao suicídio universal imaginado por Eduard von Hartmann.

Freud: A humanidade não escolhe o suicídio porque a lei do seu ser desaprova a via direta para o seu fim. A vida tem que completar o seu ciclo de existência. Em todo ser normal, a pulsão de vida é forte o bastante para contrabalançar a pulsão de morte, embora no final esta resulte mais forte. Podemos entreter a fantasia de que a Morte nos vem por nossa própria vontade. Seria mais possível que pudéssemos vencer a Morte, não fosse por seu aliado dentro de nós. Neste sentido (acrescentou Freud com um sorriso) pode ser justificado dizer que toda a morte é suicídio disfarçado.

[Estava ficando frio no jardim. Prosseguimos a conversa no gabinete. Vi uma pilha de manuscritos sobre a mesa, com a caligrafia clara de Freud].

Jornalista: O senhor está praticando muita psicanálise?

Freud: Certamente. Neste momento estou trabalhando num caso muito difícil, tentando desatar conflitos psíquicos de um interessante novo paciente. Minha filha também é psicanalista, como você vê...

[Nesse ponto apareceu Miss Anna Freud, acompanhada por seu paciente, um garoto de onze anos, de feições inconfundivelmente anglo-saxônicas].

Jornalista: O senhor já analisou a si mesmo?

Freud: Certamente. O psicanalista deve constantemente analisar a si mesmo. Analisando a nós mesmos, ficamos mais capacitados a analisar os outros. O psicanalista é como bode expiatório dos hebreus. Os outros descarregam seus pecados sobre ele. Ele deve praticar sua arte à perfeição para desvencilhar-se do fardo jogado sobre ele.

[Apesar da sua integridade, Freud é a urbanidade em pessoa. Ele ouve pacientemente cada intervenção, não procurando jamais intimidar o entrevistador. 
Raro é o visitante que deixa sua presença sem algum presente, algum sinal de hospitalidade! Havia escurecido. Era tempo de eu tomar o trem de volta à cidade que uma vez abrigara o esplendor imperial dos Habsburgos. Acompanhado da esposa e da filha, Freud desceu os degraus que levavam do seu refúgio na montanha à rua, para me ver partir. Ele me pareceu cansado e triste, ao dar o seu adeus].

Freud: Não me faça parecer um pessimista [disse ele após o aperto de mão]. Eu não tenho desprezo pelo mundo. Expressar desdém pelo mundo é apenas outra forma de cortejá-lo, de ganhar audiência e aplauso. Não, eu não sou um pessimista, enquanto tiver meus filhos, minha mulher e minhas flores! Não sou infeliz - ao menos não mais infeliz que os outros.

[O apito do meu trem soou na noite. O automóvel me conduzia rapidamente para a estação. Aos poucos o vulto ligeiramente curvado e a cabeça grisalha de Sigmund Freud desapareceram na distância].

\section{Ilações finais}

Ali está Freud, com 70 anos, sentado atrás daquele jovem americano e paranóico de apenas, digamos, 20 anos: 50 é a diferença de idade! Nacionalidades diferentes: um austríaco atende um jovem de um país que, em grande medida, despreza. Paciente entre a neurose e a psicose, sem falar da perversão fetichista: desafio ao seu pensamento e técnica. Biografias certamente diferentes. Não é difícil imaginar o estóico Freud procurando se esquivar da ação impressionantemente perscrutadora do jovem paranóico. Mesmo com todo o manejo, o paciente invade o analista. Muito trabalho elaborativo é necessário para se livrar dos fardos lançados sobre o "bode expiatório" analista. Freud prefere atendê-lo em Viena, mas também o atende nas montanhas. Ele quer odiá-lo, mas também se afeiçoa a ele. Quer desistir, mas continua o tratamento. Deseja sua ruína, mas com o jovem americano luta como quem luta pela própria vida. Em cada ruga da face do velho de Viena e de Semmering se escondem as dores da morte da filha e do neto, dos discípulos que o deixaram, o enorme incômodo da prótese e do próprio câncer. É a luta com a vida e com a morte. A revolução intelectual que começa com "Além do princípio do prazer” em 1920 chega a pleno desenvolvimento com “O mal-estar na civilização” em 1929: no nível manifesto a guerra, a pulsão de morte na teoria. Duelo de titãs: eros e thanatos. Daqui a pouco, de Semmering Freud toma o seu trem, com seus livros e escritos, ao lado de Marta e Anna. Retorna a Viena, ao lado do majestoso Rio Danúbio. 
Pacientes como AB continuam freqüentando os consultórios dos analistas ainda hoje: personalidades com problemáticas narcísicas e esquizóides. São pacientes sem uma delimitação clara em muitos sentidos, com deficiências nas fronteiras entre o mundo interno e externo. Idéias delirantes, esvaziamento do eu, senso de realidade muito prejudicado. No tratamento há súbitas mudanças de humor e funcionamento que colocam ao analista questões difíceis de manejo. O frágil eu do paciente se sente inundado pelo mundo pulsional; o mundo e o próprio analista inundados pelas manifestações do paciente. O funcionamento pode se tornar paranóide. O caráter pendular dos movimentos do paciente podem deixar o observador/analista perplexo: comportamento paradoxal. O desespero do paciente atinge ao analista. A situação demanda que o analista se torne mais plástico, mais poroso, até talvez mais vacilante para poder acompanhar um ego que só conhece a dilaceração e a dissociação, que nunca chega a se tornar conflito. O desamparo do paciente por vezes se torna ainda que de forma mitigada o desamparo do analista. Tudo isto terá Freud de forma parcial ou integral experimentado com AB? Não sabemos, talvez. Sabemos apenas que Freud e AB foram transformados pelo tratamento.

\section{Referências}

Birman, Joel. Desejo e promessa, encontro impossível: o discurso freudiano sobre a religião. In: Moura, J. C. (org.). Pelegrino, Hélio. A-Deus. Petrópolis: Vozes, 1988.

Fenichel, Otto. Teoria psicanalítica das neuroses. São Paulo: Atheneu, 1973.

FigueIREdo, Luis Cláudio. Psicanálise - Elementos para a clínica contemporânea. São Paulo: Escuta, 2003.

Freud, Sigmund (1926). A questão da análise leiga. In: Edição Standard Brasileira das Obras Psicológicas Completas de Sigmund Freud. Rio de Janeiro: Imago, 1996. v. XX. (1926). Inibições, sintomas e ansiedade. In: Edição Standard Brasileira das Obras Psicológicas Completas de Sigmund Freud. Rio de Janeiro: Imago, 1996.

(1916). Karl Abraham. In: Edição Standard Brasileira das Obras Psicológicas Completas de Sigmund Freud. Rio de Janeiro: Imago, 1996.

Freud \& Pfister. Cartas, 1909-1939. Um diálogo entre a psicanálise e a fé cristã. Viçosa: Ultimato, 1998.

GaY, Peter. Freud: uma vida para o nosso tempo. São Paulo: Companhia das Letras, 1989.

JonEs, Ernest. A vida e a obra de Sigmund Freud. Rio de Janeiro: Imago, 1989. v. III. 
Laplanche, Jean e Pontalis, J.-B. Vocabulário da psicanálise. São Paulo: Martins Fontes, 1992.

Roazen, Paul. Como Freud trabalhava. São Paulo: Companhia das Letras, 1999.

RodRIGuÉ, Emilio. Sigmund Freud. O século da psicanálise, 1895-1995. São Paulo: Escuta, 1995. v. 3.

VIEREck, George S. Entrevista com Freud, Alpes Austríacos, 1926. Tradução de Paulo César Souza.

WondraceK, Karin. O amor e seus destinos. A contribuição de Oskar Pfister para o diálogo entre teologia e psicanálise. São Leopoldo: Sinodal, 2005.

\section{Resumos}

El articulo recupera un desconocido caso de Freud, del cual la correspondencia Freud \& Pfister da fragmentarias noticias. Las cartas intercambiadas entre 1924 y 1927 fornecen informaciones sobre la derivación, la difícil evolución del tratamiento de $A B$ e el sufrimiento de Freud al atenderlo. Los avances y retrocesos del problemático caso están relacionados con las vicisitudes de la vida de Freud, con los progresos del psicoanálisis y con los acontecimientos sociales y políticos de la época. Pacientes como $A B$, con problemáticas narcísistas y esquizoides, afirma el artículo, continúan llegando a los consultorios de los analistas hoy en día.

Palabras claves: Caso AB, correspondencia Freud \& Pfister, historia del psicoanálisis, personalidades narcísicas y esquizoides

Cet article récupère un cas inconnu de Freud, dont la correspondance entre Freud et Pfister donne des informations fragmentaires. Les lettres échangées entre 1924 et 1927 fournissent des informations sur l'orientation du patient, l'évolution difficile du traitement de $A B$ et la souffrance de Freud lors des séances. Les progrès et les reculs de ce cas problématique sont liés aux vicissitudes de la vie de Freud, aux progrès de la psychanalyse et aux événements socio-politiques de l'époque. Des patients comme $A B$, ayant des problèmes narcissiques et schizoïdes, tel l'affirme cet article, continuent de se présenter, aujourd'hui, aux cabinets des analystes.

Mots clés: Cas AB, correspondance Freud \& Pfister, histoire de la psychanalyse, personnalités narcissiques et schizoïdes

This article describes a little-known case treated by Freud, known as the AB Case, about which the correspondence between him and Pfister gives us some fragmentary information. The letters these friends exchanged between 1924 and 1927 discuss 
Pfister's referral of the young patient to Freud, the difficult treatment involved and Freud's suffering during the process. The article associates the advances and setbacks in this complex case, related to Freud's personal difficulties at the time as well as with advances in psychoanalysis and with the social and political events of the period. Patients like $A B$, who show narcissistic and schizoid traits, still continue to arrive at analysts'offices today.

Key words: AB case, correspondence between Freud \& Pfister, history of psychoanalysis, narcissistic and schizoid personalities

\section{SÉrgio de GouvÊa Franco}

Psicanalista com prática clínica em São Paulo, doutor pela Unicamp (Campinas, SP, Brasil) e pós-doutor em psicologia clínica pela PUC-SP; membro da Associação Universitária de Pesquisa em Psicopatologia Fundamental; professor titular de psicologia da Unip (Avenida Torres de Oliveira, 330, Jaguaré 05347-020 São Paulo, SP, Brasil); reitor da Fecap (Avenida Liberdade, 532, Liberdade 01502-001 São Paulo, SP, Brasil); autor do livro Hermenêutica e Psicanálise na Obra de Paul Ricoeur e de vários artigos publicados em coletâneas, revistas brasileiras e estrangeiras; membro do Departamento de Psicanálise do Instituto Sedes Sapientiae (São Paulo, SP, Brasil).

Av. Onze de junho, 1291/42

04041-054 São Paulo, SP, Brasil

e-mail: sgfranco@attglobal.net

\section{KARIN WONDRACEK}

Psicanalista com prática clínica em Porto Alegre; psicóloga; membro titular do Núcleo de Estudos Sigmund Freud (Porto Alegre, RS, Brasil); tradutora com Ditmar Junge das Cartas entre Freud e Pfister, (1998, Ultimato); organizadora de O futuro e a ilusão: um embate com Freud sobre psicanálise e religião (2003, Vozes); com dissertação de mestrado sobre Oskar Pfister ( $O$ amor e seus destinos: a contribuição de Oskar Pfister para o diálogo entre psicanálise e teologia. Sinodal, 2005); vice-coordenadora do Grupo Independente de Pesquisa em Psicanálise e Religião (Porto Alegre, RS, Brasil) e pesquisadora desta temática no doutorado em curso no IEPG (São Leopoldo, RS, Brasil), onde é docente.

Rua Carlos von Koseritz, 1336

90540-030 Porto Alegre, RS, Brasil

e-mail: karinkw@gmail.com

Versão inicial recebida em setembro de 2007 Versão aprovada para publicação em novembro de 2007 